Abstracta Iranica Abstranica

Revue bibliographique pour le domaine irano-aryen

Volume 29 | 2008

Comptes rendus des publications de 2006

\title{
« Putin, Ahmadinejad and the Iranian Nuclear Crisis ». Middle East Policy Council Journal, volume XIII, N${ }^{\circ}$, hiver 2006, pp. 15-28.
}

\section{Anicée Van Engeland}

\section{OpenEdition}

Journals

Édition électronique

URL : http://journals.openedition.org/abstractairanica/32422

DOI : 10.4000/abstractairanica.32422

ISSN : 1961-960X

Éditeur :

CNRS (UMR 7528 Mondes iraniens et indiens), Éditions de l'IFRI

\section{Édition imprimée}

Date de publication : 15 mai 2008

ISSN : 0240-8910

Référence électronique

Anicée Van Engeland, « «Putin, Ahmadinejad and the Iranian Nuclear Crisis ». Middle East Policy Council Journal, volume XIII, N4, hiver 2006, pp. 15-28. », Abstracta Iranica [En ligne], Volume 29 | 2008, document 371, mis en ligne le 15 septembre 2008, consulté le 26 septembre 2020. URL : http:// journals.openedition.org/abstractairanica/32422; DOI : https://doi.org/10.4000/abstractairanica. 32422

Ce document a été généré automatiquement le 26 septembre 2020

Tous droits réservés 


\title{
« Putin, Ahmadinejad and the Iranian Nuclear Crisis ». Middle East Policy Council Journal, volume XIII, $\mathrm{N}^{\circ} 4$, hiver 2006, pp. 15-28.
}

\author{
Anicée Van Engeland
}

L'élection du Président Ahmadinejad a représenté tout à la fois des défis et des opportunités pour le Président Poutine. L'article analyse la politique de la Russie depuis l'élection de Mahmoud Ahmadinejad en juin 2005. L'A. travaille en particulier sur les problématiques liées aux relations irano-russes et étudie notamment la question nucléaire. La conclusion de Mark Katz est que les relations entre les deux dirigeants sont tendues : Moscou est frustré par les décisions politiques d'Ahmadinejad. Cependant, la Russie ne soutient pas la politique américaine à l'égard de l'Iran. La raison est économique: la Russie ne voudrait pas perdre les avantages économiques qu'elle a en Iran.

\section{INDEX}

Thèmes : 13.1. Iran 


\section{AUTEURS}

ANICÉE VAN ENGELAND

European University Institute - Florence 